\title{
Reducing medication errors at transitions of care is everyone's business
}

\section{SUMMARY}

Medication errors are a common and significant problem, particularly when patients transition between healthcare providers. Discrepancies are especially prevalent on hospital admission and discharge.

People with complex medication regimens, older people, those with mental health problems, people who are poor or have low literacy, and Aboriginal and Torres Strait Islander and migrant populations are particularly at risk of medication discrepancies.

A patient-centred approach is a necessary shift towards reducing medication discrepancies and errors. The patient is the one 'constant' as they progress through GP and ancillary primary care services, hospital services, and specialist outpatient and private clinics. Patients and their carers need to be involved as active participants in this process.

Maintaining an accurate, comprehensive and up-to-date medicines list that follows the patient, reduces serious medication error. Pivotal to this record is a medicines reconciliation review at error-prone transition points.

Multiple health professionals involved in a patient's journey through healthcare services need to embrace accountability for medicines-related outcomes. Emerging technologies for communication between primary care and specialist or secondary services will facilitate this, but importantly, there needs to be commitment from each health professional to undertake this approach.

\section{Introduction}

As patients move between health providers and settings, discrepancies and miscommunication in clinical records are common and lead to serious medication errors. ${ }^{1,2}$ Hospital admissions and discharges, interdepartmental transfers, or care shared between a specialist and a GP, are often dangerous times for patients, especially those with long-term conditions or taking multiple medicines. ${ }^{3}$

\section{A 2017 report by the World Health Organization} on medication safety emphasised that improving communication at transition points is vital to avoiding medication-related harm. ${ }^{4}$ Also, a recent commentary has highlighted the need for better transitional care in Australia to reduce the significant costs of medication mismanagement, including avoidable hospital (re)admissions. ${ }^{3}$ For example, poor medication management during or immediately after hospital admission increased the risk of readmission in the next month by $28 \%{ }^{5}$

\section{The size of the problem}

Discrepancies in medicine records can occur at every level of care. There are significant discrepancies between the medicines people take at home, the medicines GPs think they are taking at home, medicines listed in GP referral letters, medicines people obtain from pharmacies, the medicines recorded when they are admitted to hospital, and when they leave hospital, and the medicines detailed in their official discharge summary. These discrepancies often relate to medicine omissions. ${ }^{6-8}$ In mental health community care, medication discrepancies cause particular problems. Psychiatrists often remain involved in prescribing and reviewing psychotropic medicines, while GPs are expected to manage medicines related to other conditions. Patients may take a number of medicines in complex regimens so there is a high potential for drug interactions, particularly given the substantial comorbidity and mortality rates in this population. ${ }^{9,10}$ Recent research on clozapine has shown that discrepancies with concomitant medications can have potentially fatal outcomes (see Box). .11, $^{12}$

Indigenous or migrant people, and those who are socially disadvantaged or have low literacy, experience health outcomes that reflect their difficulties when navigating the healthcare system. ${ }^{13-16}$ Culturally appropriate delivery of health services is crucial to effective engagement and uptake, and this may be challenging to do well.

\section{Amanda J Wheeler}

Professor of Mental Health Menzies Health Institute

Queensland

Griffith University

Brisbane

\section{Shane Scahill}

Senior lecturer Health Services Management and Entrepreneurship School of Management Massey University New Zealand

\section{David Hopcroft}

General practitioner

Auckland

New Zealand

\section{Helen Stapleton}

Student support and

Research educator

Mater Education

Brisbane

\section{Keywords}

electronic medical records, medication errors, MedicineWise app, My Health Record, patient discharge, transitions of care

Aust Prescr 2018:41:73-7 https://doi.org/10.18773/ austprescr.2018.021 


\section{Box Medication discrepancies with clozapine in a shared-care program}

Clozapine is the most effective antipsychotic for treatment-resistant schizophrenia However, its use is restricted because of potentially fatal adverse effects (including agranulocytosis, myocarditis, gastrointestinal hypomotility and severe constipation) and the requirement for mandatory monitoring. Pharmacokinetic and dynamic interactions can alter clozapine levels and cause additive adverse effects (e.g. concomitant medicines that cause constipation, such as codeine, can cause fatal bowel obstruction ${ }^{12}$ ). Clozapine prescribing is commonly restricted to psychiatrists and dispensed by a hospital pharmacy. In a shared-care model with the specialist, a GP may prescribe maintenance treatment. The mandatory 4-weekly well-being and haematological monitoring is undertaken by the GP who instructs the hospital pharmacy to dispense the prescription and arrange delivery to the local community pharmacy for the consumer to pick up. The psychiatrist reviews the patient quarterly, which reduces the number of hospital appointments and associated time and cost burdens. This model also promotes primary care relationships and physical health management.

However, the very high rates of medication discrepancies identified across shared-care medication records in a Queensland service are of significant concern." Overall, 32/35 patients had at least one medication discrepancy, mostly omissions, with an average of 4.9 per consumer. Specialist records had the highest number of discrepancies (74\%), followed by GP records (70\%) and community pharmacy (62.5\%)."
People with chronic conditions and multiple medications from multiple prescribers, particularly older people, are another group who are likely to have incomplete or incorrect medicine lists. It is important to focus on these vulnerable groups if we are to reduce medication errors.

\section{Patient-centred approaches lead to patient-centred outcomes}

The key to reducing serious medication errors and patient harm is to ensure timely, accurate handover of medicines at all transition points in care. Smooth transitions require competent and coordinated responses from health professionals focused on the individual's needs. ${ }^{3,4,6}$ The one person who remains constant is the patient, who has the most to lose in a disconnected health system. Patients and their carers need to be actively involved in the management of their medicines and transfer of information.

\section{Improving medicines communication during transitions}

In Australia, strategies to improve communication at transition points have been trialled. They include medication reconciliation and discharge planning in hospital settings, electronic prescribing, personal electronic health records (My Health Record) and collaborative medicines review in the community. ${ }^{6}$

\section{Medicines reconciliation}

Medicines reconciliation involves matching the medicines the person should be prescribed to those they are actually prescribed. ${ }^{17}$ The verified information must include reasons for changes made to medicines during an episode of care, which must be shared with the next care provider. It is commonly undertaken during inpatient visits and studies have shown it significantly reduces medication error ${ }^{18,19}$ and improves patient outcomes. ${ }^{20}$ Patients are integral to the process by providing their current medicine list (on paper, as a photo or on a smartphone app such as MedicineWise), or the medicines themselves. They also need to be provided with education and an updated list at discharge or whenever medicines are changed.

The reconciliation process helps to identify problems such as drug interactions and risk of adverse events. ${ }^{18}$ Ideally, it should occur at each episode of care and upon transfer to the next care provider, and patients and their carers should be fully involved.

While hospital pharmacists have played a leading role, ${ }^{6}$ medicines reconciliation is everybody's business and training is needed for the whole clinical team. 2,19,21-24

\section{Discharge planning}

It is just as important to ensure accurate and timely transfer of information at hospital discharge as it is on admission. Providing a Pharmaceutical Benefits Scheme (PBS) prescription on discharge for one month's supply should be reconciled by a pharmacist against the Discharge Medication Record, to ensure that patients have access to any new or changed medicines and an adequate supply of continuing medicines. The hospital pharmacist can liaise with the patient's community pharmacist to organise dispensing in the community, particularly if a dose administration aid is needed. It also allows the pharmacist to provide the consumer with information to manage their medicines (e.g. with their own copy of the Discharge Medication Record). This process allows time for the discharge summary communicating the current medication plan to reach the GP before a new prescription is needed. However, effective discharge planning requires cooperation between doctors, pharmacists and nurses in the hospital and community.

\section{Electronic prescribing}

As part of electronic medication management systems, e-prescribing can enhance safety and quality by ensuring complete and legible orders, and reducing medication errors and adverse reactions. However, e-prescribing systems can introduce new types of errors such as incorrect selection of medicines from drop-down menus. ${ }^{25}$ They need to be integrated with other systems to provide clinical decision support and easy exchange of patient data between GPs, secondary or specialist care and shared personal health records. These systems 
need to ensure medication selection processes are safe, for example provide warnings if a medicine is contraindicated, or when a medicine is similar in name to another, or dosing is potentially harmful. Warnings also need to be prioritised so they are not ignored. With many different e-prescribing systems available, national standards to ensure safety and quality criteria are vital. 26,27

\section{Personal electronic health records}

Stronger linkages between primary and secondary care, particularly for people transitioning between outpatient specialists and GPs, are needed (see Box). Linked and controlled electronic patient management systems are a partial solution, and My Health Record is a step toward this notion of integration. This will be the main conduit in Australia for an integrated system. As it will become an opt-out model, significant uptake in the national roll-out is expected. ${ }^{28}$ Clearly, appropriate controls governing security, access and privacy are paramount but these are manageable. Such systems are operational in other developed countries (such as New Zealand) where security and privacy are managed through automated security detection which highlights when patient files have been accessed by those practitioners (or other health workers) who should not have access. When notified files have been inappropriately accessed, review and due process are undertaken by the relevant agency.

With My Health Record, access and privacy are driven by the consumer. ${ }^{29}$ They can set a record access code which they give to their healthcare providers to allow them to view their records. This prevents other healthcare providers from access unless in an emergency. Consumers can also flag specific documents in their record as 'limited access', and control who can view these documents.

My Health Record is an online summary of a person's individual real-time health information. Primary digital health records will still be maintained at source, including general practices and hospitals. Medicines information, including PBS dispensing information (from the last two years), GP electronic prescriptions, pharmacy dispensing records, electronic hospital discharge summaries and specialist letters will be available from multiple sources in a Medicines Information view. ${ }^{30}$

While ease of access to medicines information for consumers moving between multiple prescribers is a significant step forward, information may be incomplete. For example, medicines that have been stopped, or doses changed, may not be reflected in prescription or dispensing records. Practitioners' notes may not have been uploaded and made available via the Medicines Information view. Also, consumers may have removed prescription and dispensing information in their record. ${ }^{31}$ The vital element in all transitions of care is accurate and timely communication between patients, their carers, and health practitioners. This helps to confirm and validate information contained in the shared electronic health record.

\section{Medicines reviews}

Home Medicines Reviews (and Residential Medication Management Reviews conducted in aged-care facilities) are additional avenues to improve medicines reconciliation in primary care. ${ }^{6,32}$ The GP, patient and an accredited pharmacist collaborate to identify and resolve medication-related problems, particularly following hospital discharge or significant changes to a patient's condition or medicine regimen. ${ }^{33}$ Studies report improvements in prescribing and health outcomes (including costs) by reducing medicationrelated problems. Reviews undertaken shortly after hospital discharge have also been shown to reduce adverse events and provide an opportunity for medicines reconciliation. ${ }^{32}$ Although research has shown that Home Medicines Reviews reduce hospital admissions for people on high-risk medicines, the current funding cap and referral pathways restrict access to the program..$^{16}$ This is particularly notable for Aboriginal and Torres Strait Islander people who experience multiple barriers to accessing existing medicines review programs. ${ }^{34}$ Over the next two years a study in nine Aboriginal Health Services will assess the feasibility of community pharmacists delivering an individualised, culturally appropriate medicines review to resolve medication-related problems and reduce hospitalisations. ${ }^{35}$

Another avenue to improve medicines reconciliation in primary care is currently being trialled in Queensland. ${ }^{36}$ A non-dispensing pharmacist based within a general practice will conduct a review within a week of discharge, reconciling any differences between the discharge summary and the practice medical records. A pharmacist consultation with the patient will be followed directly by a GP appointment, and any anomalies clarified. The aim of this study is to reduce unplanned readmissions to hospital.

\section{Health service delivery: structure and agency}

A focus on avoiding costly hospital admissions and providing high-quality, patient-centred care in the community is challenging, particularly in light of an ageing and expanding population of people with multiple long-term conditions. An OECD Health Care Quality Review found that Australia needs to strengthen its primary care system to better coordinate consumer care. It emphasises the role 
of GPs and promotes a system that enables people to access care from a multidisciplinary team of health professionals. ${ }^{37}$

Any service reconfigurations centred on improving medication safety must consider the complexities associated with prescribing and supply. The physical (structure) and human aspects (agency) of health service delivery are equally important when it comes to service design and delivery. Physical elements focus on the geographical location of healthcare providers. Co-location of the GP, pharmacy and specialists generally improves communication and teamwork in primary care. ${ }^{38}$ Australia started twoyear trials of Health Care Homes in general practices in July 2017.39

Patient care pathways must be integrated through the health sectors. Electronically shared records would facilitate easy transfer of correct, real-time information.

In order to improve Australia's fragmented health system, the OECD recommended devolving responsibility for delivering primary care to the states and territories. ${ }^{37}$ For example, building on the primary care collaboratives ${ }^{40}$ and practice incentives program, ${ }^{37,41}$ Primary Health Networks could have greater responsibility in creating more effective and efficient systems in their regions which are tailored to local needs, with accountability for reducing hospital admissions. ${ }^{42}$ This should be underpinned by seamless integration of care between healthcare professionals and the use of technology. Clinical records and a single medication record should follow the patient.

At the clinical professional level (i.e. agency), a culture of teamwork and shared accountability needs to be actively promoted. Professional boundaries and competition, among health professionals and between health practitioners and managers, need to be dissolved. ${ }^{43}$ In hospitals, practitioners work largely in multidisciplinary teams. However, in primary care, and at the interface between primary and specialist or secondary care, this level of collaboration and trust is often more difficult to initiate and sustain.

\section{Conclusion}

Medication discrepancies and errors arising from lack of care coordination for healthcare consumers seeing multiple prescribers is a very real problem. A patient-centred approach is key to improvement, along with strategies including integrated care pathways facilitated by technology and shared accountability. All healthcare providers need to commit to the consumer being central to the goal of medications accuracy. $\varangle$

\section{REFERENCES}

1. Procyshyn RM, Barr AM, Brickell T, Honer WG. Medication errors in psychiatry: a comprehensive review. CNS Drugs 2010;24:595-609. https://doi.org/10.2165/ 11533710-000000000-00000

2. Australian Commission on Safety and Quality in Health Care. High 5 s project. Assuring medication accuracy at transitions of care - Australian Interim Report, January 2010 - March 2013. Sydney: ACSQHC; 2014. https://safety.clientpreview.com.au/our-work/medicationsafety/medication-reconciliation/who-high-5s-projectreports [cited 2018 May 1]

3. Wells L, Dawda P, Knight A. Hospital discharge: a dangerous time for patients. MJA InSight 2017 May 15, Issue 18. www.doctorportal.com.au/mjainsight/2017/18/hospitaldischarge-a-dangerous-time-for-patients [cited 2018 May 1]

4. World Health Organization. Medication without harm Global patient safety challenge on medication safety. Geneva: WHO; 2017. http://www.who.int/patientsafety/ medication-safety/en [cited 2018 May 1]

5. Feigenbaum P, Neuwirth E, Trowbridge L, Teplitsky S, Barnes CA, Fireman E, et al. Factors contributing to all-cause 30-day readmissions: a structured case series across 18 hospitals. Med Care 2012;50:599-605. https://doi.org/ 10.1097/MLR.0b013e318249ce72

6. Roughead L, Semple S, Rosenfeld E. Literature review: medication safety in Australia. Sydney: Australian Commission on Safety and Quality in Health Care; 2013 https://www.safetyandquality.gov.au/publications/ literature-review-medication-safety-in-australia [cited 2018 May 1]

7. Belleli E, Naccarella L, Pirotta M. Communication at the interface between hospitals and primary care - a general practice audit of hospital discharge summaries. Aust Fam Physician 2013;42:886-90.

8. Carney SL. Medication accuracy and general practitioner referral letters. Intern Med J 2006;36:132-4. https://doi.org/ 10.1111/j.1445-5994.2006.01022.x
9. Australian Institute of Health and Welfare. Comorbidity of mental disorders and physical conditions 2007. Canberra: AlHW; 2012. https://www.aihw.gov.au/reports/primaryhealth-care/comorbidity-of-mental-disorders-and-physicalcondi/contents/publication [cited 2018 May 1]

10. Lawrence D, Hancock KJ, Kisely S. The gap in life expectancy from preventable physical illness in psychiatric patients in Western Australia: retrospective analysis of population based registers. BMJ 2013;346:f2539. https://doi.org/ 10.1136/bmj.f2539

11. Murphy K, Coombes I, Moudgil V, Patterson S, Wheeler A. Clozapine and concomitant medications: assessing the completeness and accuracy of medication records for people prescribed clozapine under shared care arrangements. J Eval Clin Pract 2017;23:1164-72. https://doi.org/10.1111/jep.12743

12. Every-Palmer S, Nowitz M, Stanley J, Grant E, Huthwaite M, Dunn $\mathrm{H}$, et al. Clozapine-treated patients have marked gastrointestinal hypomotility, the probable basis of lifethreatening gastrointestinal complications: a cross sectional study. EBioMedicine 2016;5:125-34. https://doi.org/10.1016/ j.ebiom.2016.02.020

13. Babar ZU, Pengelly K, Scahill SL, Garg S, Shaw J. Migrant health in New Zealand: exploring issues concerning medicines access and use. J Pharm Health Serv Res 2013;4:41-9. https://doi.org/10.1111/j.1759-8893.2012.00105.x

14. Australian Commission on Safety and Quality in Health Care. Consumers, the health system and health literacy: taking action to improve safety and quality. Consultation Paper. Sydney: ACSQHC; 2013. https://www.safetyandquality.gov.au/ our-work/patient-and-consumer-centred-care/health-literacy/ consumers-the-health-system-and-health-literacy-takingaction-to-improve-safety-and-quality-3 [cited 2018 May 1]

15. Australian Government Department of Health. National Aboriginal and Torres Strait Islander Health Plan 2013-2023. Canberra: Commonwealth of Australia; 2013. p. 14-23. http://www.health.gov.au/natsihp [cited 2018 May 1] 
16. Paola S. The big debate: HMR versus MedsCheck. AJP Online 2017 Jun 26. https://ajp.com.au/news/big-debate-hmrversus-medscheck [cited 2018 May 1]

17. Australian Commission on Safety and Quality in Health Care. Medication reconciliation. Sydney: ACSQHC; 2018. wWw.safetyandquality.gov.au/our-work/medication-safety/ medication-reconciliation [cited 2018 May 1].

18. Duguid $M$. The importance of medication reconciliation for patients and practitioners. Aust Prescr 2012;35:15-9. https://doi.org/10.18773/austprescr.2012.007

19. Brownlie K, Schneider C, Culliford R, Fox C, Boukouvalas A Willan $C$, et al. Medication reconciliation by a pharmacy technician in a mental health assessment unit. Int J Clin Pharm 2014;36:303-9. https://doi.org/10.1007/ s11096-013-9875-8

20. Stowasser DA, Collins DM, Stowasser M. A randomised controlled trial of medication liaison services - patient outcomes. J Pharm Pract Res 2002;32:133-40. https://doi.org/10.1002/jppr2002322133

21. Young L, Barnason S, Hays K, Do V. Nurse practitionerled medication reconciliation in critical access hospitals. J Nurse Pract 2015:11:511-8. https://doi.org/10.1016/ j.nurpra.2015.03.005

22. Tong EY, Roman CP, Mitra B, Yip GS, Gibbs H, Newnham HH, et al. Reducing medication errors in hospital discharge summaries: a randomised controlled trial. Med J Aust 2017;206:36-9. https://doi.org/10.5694/mja16.00628

23. Cresswell A, Hart M, Suchanek O, Young T, Leaver L, Hibbs S. Mind the gap: improving discharge communication between secondary and primary care. BMJ Qual Improv Rep 2015:4:u207936.w3197. https://doi.org/ 10.1136/bmjquality.u207936.w3197

24. Feldman LS, Costa LL, Feroli ER Jr, Nelson T, Poe SS, Frick KD, et al. Nurse-pharmacist collaboration on medication reconciliation prevents potential harm. J Hosp Med 2012;7:396-401. https://doi.org/10.1002/jhm.1921

25. Redwood S, Rajakumar A, Hodson J, Coleman JJ. Does the implementation of an electronic prescribing system create unintended medication errors? A study of the sociotechnical context through the analysis of reported medication incidents. BMC Med Inform Decis Mak 2011;11:29. https://doi.org/10.1186/1472-6947-11-29

26. Australian Commission on Safety and Quality in Health Care. Electronic medication management systems: a guide to safe implementation. 2nd ed. Sydney: ACSQHC; 2012. https://www.safetyandquality.gov.au/our-work/medicationsafety/electronic-medication-management/electronicmedication-management-systems-a-guide-to-safeimplementation [cited 2018 May 1]

27. Sweidan M, Williamson M, Reeve JF, Harvey K, O'Neill JA Schattner $\mathrm{P}$, et al. Identification of features of electronic prescribing systems to support quality and safety in primary care using a modified Delphi process. BMC Med Inform Decis Mak 2010;10:21. https://doi.org/ 10.1186/1472-6947-10-21

28. Australian Government Department of Health. My Health Record - continuation and expansion. 2017 May 9. http://www.health.gov.au/internet/budget/publishing.nsf/ Content/budget2017-factsheet47.htm [cited 2018 May 1]

29. My Health Record, Australian Digital Health Agency. Managing access, privacy and security. 2016 Apr 3. https://myhealthrecord.gov.au/internet/mhr/publishing.nsf/ Content/privacy [cited 2018 May 1]
30. My Health Record, Australian Digital Health Agency. A new Medicines Information view in the My Health Record. 2017 Jun 16. https://myhealthrecord.gov.au/internet/mhr/ publishing.nsf/Content/news-031 [cited 2018 May 1]

31. My Health Record, Australian Digital Health Agency. Prescription and dispense record. https://myrecord.ehealth. gov.au/portal/help/medicines_information/medicines [cited 2018 May 1]

32. Rigby D. Collaboration between doctors and pharmacists in the community. Aust Prescr 2010;33:191-3. https://doi.org/ 10.18773/austprescr.2010.088

33. 6th Community Pharmacy Agreement. Program rules. http://6cpa.com.au/resources/program-rules [cited 2018 May 1]

34. Swain LS, Barclay L. Exploration of Aboriginal and Torres Strait Islander perspectives of Home Medicines Review. Rural Remote Health 2015;15:3009.

35. 6th Community Pharmacy Agreement. Indigenous medication review service feasibility study. http://6cpa.com au/pharmacy-trial-program/indigenous-medication-reviewservice-feasibility-study [cited 2018 May 1]

36. Foot H, Freeman C, Hemming K, Scott I, Coombes ID, Williams ID, et al. Reducing Medical Admissions into Hospital through Optimising Medicines (REMAIN HOME) study: protocol for a stepped-wedge, cluster-randomised trial. BMJ Open 2017;7:e015301. https://doi.org/10.1136/ bmjopen-2016-015301

37. Organisation for Economic Co-operation and Development. OECD Reviews of Health Care Quality. Australia 2015: Raising Standards. Paris: OECD; 2015. https://doi.org/10.1787/ 9789264233836-en

38. Bradley F, Elvey R, Ashcroft DM, Hassell K, Kendall J, Sibbald B, et al. The challenge of integrating community pharmacists into the primary health care team: a case study of local pharmaceutical services (LPS) pilots and interprofessional collaboration. J Interprof Care 2008;22:387-98. https://doi.org/10.1080/13561820802137005

39. Ley S. Health care homes to keep chronically-ill out-ofhospital [media release]. 2016 Mar 31. www.health.gov.au/ internet/ministers/publishing.nsf/Content/health-mediarelyr2016-ley024.htm [cited 2018 May 1]

40. Knight AW, Caesar C, Ford D, Coughlin A, Frick C. Improving primary care in Australia through the Australian Primary Care Collaboratives Program: a quality improvement report. BMJ Qual Saf 2012;21:948-55. https://doi.org/10.1136/ bmjqs-2011-000165

41. Australian Government Department of Human Services. Practice Incentives Program. https://www.humanservices. gov.au/organisations/health-professionals/services/ medicare/practice-incentives-program [cited 2018 May 1]

42. Duckett S, Swerissen $H$. Building better foundations for primary care. Melbourne: Grattan Institute; 2017. https://grattan.edu.au/report/building-better-foundations [cited 2018 May 1]

43. Degeling P, Kennedy J, Hill M. Mediating the cultural boundaries between medicine, nursing and management-the central challenge in hospital reform. Health Serv Manage Res 2001;14:36-48. https://doi.org/ $10.1177 / 095148480101400105$ 